\title{
Avaliação de probiótico na alimentação de poedeiras comerciais no segundo ciclo de postura
}

\author{
[Evaluation of probiotics in feed for laying hens in the second cycle stance] \\ R.V. Nunes ${ }^{1}$, C. Scherer ${ }^{1}$, W.T.M. Silva ${ }^{1}$, M.D. Appelt ${ }^{1}$, P.C. Pozza ${ }^{2}$, F.M. Vieites ${ }^{3}$ \\ ${ }^{1}$ Programa de pós-graduação - Universidade Estadual do Oeste do Paraná - Marechal Cândido Rondon, PR \\ ${ }^{2}$ Programa de pós-graduação - Universidade Estadual de Maringá - Maringá, PR \\ ${ }^{3}$ Programa de pós-graduação - Universidade Federal do Mato Grosso - Rondonópolis, MT
}

\begin{abstract}
RESUMO
Avaliou-se o efeito da inclusão de probiótico sobre o desempenho e a qualidade dos ovos de poedeiras semipesadas no segundo ciclo de postura. Foram utilizadas 450 aves com 69 semanas de idade, distribuídas aleatoriamente em um delineamento inteiramente ao acaso, em cinco tratamentos, seis repetições e 15 aves por unidade experimental. A ração experimental foi à base de milho e farelo de soja e suplementada com probiótico composto por Lactobacillus acidophilus, Streptococcus faecium $e$ Bifidobacterium bifidum. O experimento teve a duração de 16 semanas e foi dividido em quatro períodos de 28 dias cada, nos quais as aves receberam cinco rações experimentais contendo diferentes porcentagens de inclusão de probiótico, $0 ; 0,05 ; 0,10 ; 0,15$ e $0,20 \%$. Não foi observado efeito $(\mathrm{P}>0,05)$ da inclusão de probiótico sobre o desempenho e a qualidade dos ovos de galinhas poedeiras no segundo ciclo de postura. A inclusão de $0,10 \%$ de probiótico influenciou negativamente a gravidade específica dos ovos. A utilização de probiótico para galinhas no segundo ciclo de postura não interfere na produção e na qualidade dos ovos.
\end{abstract}

Palavras-chave: galinha, produção de ovos, qualidade de ovos, probiótico

\begin{abstract}
Evaluating the effect of the inclusion of probiotic on the performance and egg quality of laying hens in the second laying cycle, 450 birds were used at 69 weeks of age, distributed in a completely randomized design, in five treatments, six replicates and 15 poultries per experimental unit. The experimental diets were based on corn and soybean meal and supplemented with increasing levels of probiotic consisting of Lactobacillus acidophilus, Streptococcus faecium, and Bifidobacterium bifidum. The experiment lasted 16 weeks, divided into four periods of 28 days each, in which the birds were fed five experimental diets containing different percentages of probiotic inclusion, $0 ; 0.05 ; 0.10 ; 0.15$ and $0.20 \%$, in the period from 69 to 85 weeks of age. There was no effect $(P>0.05)$ of the inclusion of probiotic on performance and egg quality of laying hens in the second laying cycle. The inclusion of $0.10 \%$ of probiotic negatively influenced the specific gravity of eggs. The probiotic used for laying hens in the second cycle does not interfere in production and egg quality.
\end{abstract}

Keywords: egg production, egg quality, hens, probiotic

\section{INTRODUÇÃO}

Como ferramenta para a melhora do desempenho produtivo e da qualidade dos ovos de poedeiras em diferentes fases da vida, tem-se proposto a utilização de probióticos (Giampauli et al.,
2005), os quais proporcionam benefícios à saúde do hospedeiro, não deixam resíduos nos produtos de origem animal e não favorecem resistência às drogas (Nepomuceno e Andreatti, 2000).

Recebido em 22 de agosto de 2011

Aceito em 10 de setembro de 2012

E-mail: nunesrv@hotmail.com 
Vários microrganismos são usados como probióticos, entre eles bactérias ácido-lácticas, bactérias não ácido-lácticas e leveduras. Os probióticos devem ser inócuos, manter-se viáveis por longo tempo durante a estocagem, tolerar o baixo $\mathrm{pH}$ do suco gástrico e resistir à ação da bile e das secreções pancreática e intestinal, não transportar genes transmissores de resistência e possuir propriedades antimutagênicas e anticarcinogênicas, assim como resistir a fagos e ao oxigênio (Holzapfel e Schillinger, 2002).

Pesquisas demonstram que probióticos administrados em poedeiras durante o ciclo de produção podem melhorar as características de desempenho e qualidade de ovos. Panda et al. (2000) observaram que a suplementação de probiótico resultou no aumento da produção de ovos e da espessura da casca. Hong et al. (2002) observaram aumento na espessura da casca, na produção e no peso de ovos. Tortuero e Fernandez (1995), avaliando probióticos para poedeiras de 25 a 42 semanas de idade, observaram que a adição de Lactobacillus na ração provocou aumento na produção e no peso dos ovos, melhora na conversão alimentar e na qualidade do albúmen. Além disso, o probiótico à base de Bacillus cereus incrementou o peso dos ovos e melhorou a qualidade do albúmen.

Ao suplementarem rações de poedeiras com probiótico à base de $B$. cereus, no período de 25 a 72 semanas de idade, Panda et al. (2003) observaram aumento na concentração de cálcio sérico. Tal efeito é considerado benéfico, pois está diretamente relacionado com a melhora da qualidade da casca dos ovos, o que é desejado em poedeiras no segundo ciclo de postura. A ausência de resultados positivos com a utilização de probióticos também foi relatada. Giampauli et al. (2005) observaram que a utilização de Bacillus subtilis, nas fases de recria, postura e pós-muda, não provocou melhora no desempenho e na qualidade de ovos de poedeiras com 70 a 90 semanas de idade.

Objetivou-se avaliar o efeito de probiótico sobre o desempenho e a qualidade dos ovos de poedeiras comerciais no segundo ciclo de postura.

\section{MATERIAL E MÉTODOS}

Foram utilizadas 450 poedeiras semipesadas da linhagem Isabrown com 69 semanas de idade, alojadas em galpão tipo Califórnia, coberto com telhas de barro, quatro fileiras de gaiolas de arame, com capacidade para três aves por gaiola. $\mathrm{O}$ delineamento utilizado foi o inteiramente ao acaso, com cinco tratamentos - porcentagem de inclusão de probiótico de $0 ; 0,05 ; 0,10 ; 0,15 \mathrm{e}$ $0,20 \%$ - e seis repetições, totalizando 30 unidades experimentais, com 15 aves cada.

Com 65 semanas de idade, quando a postura se reduziu para menos de $70 \%$, as aves foram submetidas à muda forçada, utilizando-se o método adaptado de Cotta (2002). Após o período de muda, na $69^{\mathrm{a}}$ semana de idade, iniciou-se o período experimental, que teve duração de 16 semanas, subdividido em quatro períodos de 28 dias cada.

A ração experimental (Tab. 1) foi formulada à base de milho e farelo de soja e a inclusão do probiótico foi realizada em substituição ao material inerte da ração. O probiótico utilizado era composto por Lactobacillus acidophilus $\left(3,5 \times 10^{11} \quad \mathrm{UFC} / \mathrm{kg}\right) ; \quad$ Streptococcus faecium $\left(3,5 \times 10^{11} \mathrm{UFC} / \mathrm{kg}\right)$; e Bifidobacterium bifidum $\left(3,5 \times 10^{11} \mathrm{UFC} / \mathrm{kg}\right)$. As rações foram fornecidas diariamente, pela manhã, proporcionando às aves consumo de alimento e água à vontade, durante todo o período experimental, sendo a água fornecida em bebedouros tipo calha e a ração em comedouros lineares. O programa de luz utilizado foi de 17 horas diárias de iluminação.

As características avaliadas a cada período de 28 dias foram: consumo de ração, taxa de postura produção por ave/dia e produção por ave alojada -, conversão alimentar, ovos perdidos, porcentagem dos componentes dos ovos - casca, albúmen e gema -, peso da casca por unidade de superfície de área (PCSA), espessura da casca, porcentagem de matéria mineral na casca, peso dos ovos, gravidade específica e qualidade interna dos ovos - índice de albúmen, índice de gema, unidade Haugh e cor da gema.

A coleta de ovos foi realizada diariamente e o cálculo da taxa de postura baseou-se no número de ovos/ave/dia e pelo número de ovos/ave/alojada. Os ovos foram pesados nos dois últimos dias de cada período experimental. A conversão alimentar foi calculada pela divisão do consumo de ração pelo peso de ovos $(\mathrm{kg} / \mathrm{kg})$, em cada um dos quatro períodos. 
Tabela 1. Composição da ração basal utilizada para poedeiras de 69 a 85 semanas de idade com base na matéria natural

\begin{tabular}{|c|c|}
\hline Ingrediente & $\mathrm{g} / \mathrm{kg}$ \\
\hline Milho grão & 621,70 \\
\hline Farelo de soja & 260,00 \\
\hline Calcário calcítico & 90,00 \\
\hline Sal comum & 3,10 \\
\hline Fosfato bicálcico & 16,00 \\
\hline Suplemento mineral e vitamínico ${ }^{1}$ & 3,00 \\
\hline Adsorvente $^{2}$ & 3,00 \\
\hline L-Lisina.HCl & 1,00 \\
\hline Inerte & 2,20 \\
\hline Total & 1000 \\
\hline \multicolumn{2}{|l|}{ Valores calculados } \\
\hline EM (kcal/kg) & 2700 \\
\hline Proteína bruta $(\mathrm{g} / \mathrm{kg})$ & 175,89 \\
\hline Cálcio $(\mathrm{g} / \mathrm{kg})$ & 39,48 \\
\hline Fósforo disponível (g/kg) & 4,01 \\
\hline Lisina digestível (g/kg) & 9,11 \\
\hline Metionina digestível (g/kg) & 3,55 \\
\hline Met.+ Cist. digestível (g/kg) & 6,20 \\
\hline Treonina digestível (g/kg) & 6,00 \\
\hline Triptofano digestível $(\mathrm{g} / \mathrm{kg})$ & 1,88 \\
\hline Arginina Digestível (g/kg) & 10,85 \\
\hline Sódio $(\mathrm{g} / \mathrm{kg})$ & 1,40 \\
\hline \multicolumn{2}{|c|}{$\begin{array}{l}{ }^{\mathrm{T}} \text { Composição por } \mathrm{kg}: \mathrm{Mn} 33.333 \mathrm{mg} \text {, Zn } 26.667 \mathrm{mg}, \mathrm{Fe} 16.667 \mathrm{mg}, \mathrm{Cu} 2.667 \mathrm{mg}, \mathrm{I} 250 \mathrm{mg} \text {, Se } 93 \mathrm{mg} \text {, vit. A } \\
2.666,667 \mathrm{UI} \text {, vit. } \mathrm{D}_{3} 600.000 \mathrm{UI} \text {, vit. E } 1.833 \mathrm{mg} \text {, vit. } \mathrm{K}_{3} 400 \mathrm{mg} \text {, vit. } \mathrm{B}_{1} 333 \mathrm{mg} \text {, vit. } \mathrm{B}_{2} 1.000 \mathrm{mg} \text {, vit. } \mathrm{B}_{6} 567 \mathrm{mg} \text {, vit. } \\
\mathrm{B}_{12} 2.667 \mathrm{mg} \text {, ácido fólico } 93 \mathrm{mg} \text {, ácido pantotênico } 2.167 \mathrm{mg} \text {, niacina } 6.000 \mathrm{mg} \text {, colina } 25.317 \mathrm{mg} \text {, metionina } 333,33 \mathrm{~g} \text {, } \\
\text { etoxiquim } 680 \mathrm{mg} \text {, halquinol } 8.333,33 \mathrm{mg} \text {. }{ }^{2} \text { Composição por kg óxido de alumínio- } 220 \mathrm{~g} \text {, óxido de cálcio- } 10 \mathrm{~g} \text {, óxido } \\
\text { de ferro- } 20 \mathrm{~g} \text {, óxido de magnésio- } 15 \mathrm{~g} \text {, óxido de potássio- } 5 \mathrm{~g} \text {, óxido de silício- } 550 \mathrm{~g} \text {, oxido de sódio- } 10 \mathrm{~g} \text {, adsorção } \\
\text { in vitro de aflatoxina } \mathrm{B}_{1}-90 \% \text {. }\end{array}$} \\
\hline
\end{tabular}

Para avaliação da qualidade dos ovos foram utilizados quatro ovos por unidade experimental, coletados nos dois últimos dias de cada período de 28 dias. Para obtenção da porcentagem dos componentes dos ovos, obteve-se primeiramente o peso total do ovo e, em seguida, procedeu-se à quebra dele para a pesagem da gema e da casca. As cascas foram pesadas após terem sido secas em temperatura ambiente por um período mínimo de 48 horas. O peso do albúmen foi obtido pela diferença entre o peso total do ovo menos o peso da casca e da gema. Para determinação da unidade Haugh, procedeu-se à quebra dos ovos para a medição da altura de albúmen por meio de um paquímetro digital e, logo após, determinou-se a unidade Haugh utilizando-se a fórmula desenvolvida por Haugh (1937).

Os diâmetros e a altura de albúmen e de gema também foram medidos com a utilização do paquímetro para determinação dos índices de albúmen e de gema. Foi calculado o peso da casca por unidade de superfície de área (PCSA) conforme Nunes et al. (2006). Para verificar a gravidade especifica dos ovos, utilizaram-se soluções salinas com cinco concentrações distintas.

Como procedimento estatístico para comparação entre o tratamento sem inclusão de probiótico com os demais tratamentos com diferentes porcentagens de inclusão, foi utilizado o teste de Dunnett a $5 \%$ de probabilidade. Para avaliação do efeito da inclusão sobre as características avaliadas, foi realizada a análise de regressão polinomial a 5\% de significância. As análises estatísticas foram realizadas utilizando-se $\mathrm{o}$ programa SAEG (UFV, 1999). 


\section{RESULTADOS E DISCUSSÃO}

A inclusão crescente de probiótico nas rações de poedeiras semipesadas no segundo ciclo de postura não influenciou $(\mathrm{P}>0,05)$ os resultados de consumo de ração, produção por ave/dia, produção por ave alojada e conversão alimentar (Tab. 2).

Tabela 2. Consumo de ração, produção por ave/dia, produção por ave alojada e conversão alimentar, segundo a inclusão de probiótico

\begin{tabular}{lcccccc} 
& \multicolumn{5}{c}{ Inclusão de probiótico (\%) } & CV \\
\cline { 2 - 6 } & 0,00 & 0,05 & 0,10 & 0,15 & 0,20 & 117 \\
Consumo de ração (g/ave/dia) & 115 & 119 & 116 & 120 & 117 & 3,615 \\
Produção por ave/dia (\%) & 83,07 & 87,27 & 85,94 & 86,20 & 81,72 & 4,704 \\
Produção por ave alojada (\%) & 82,86 & 85,87 & 85,94 & 85,19 & 80,71 & 4,652 \\
CA (kg/kg) & 1,76 & 1,83 & 1,77 & 1,80 & 1,78 & 3,541 \\
\hline
\end{tabular}

Resultados semelhantes foram observados por Giampauli et al. (2005), que não verificaram qualquer beneficio na utilização do probiótico no consumo de ração, na produção de ovos e na conversão alimentar de poedeiras comerciais leves no segundo ciclo de postura. Utilizando dietas com probiótico fornecidas a poedeiras comerciais leves, Tortuero e Fernandez (1995) também não verificaram efeito no consumo de ração, conversão alimentar e porcentagem de postura. Da mesma forma, Pedroso et al. (2001) não observaram melhora no desempenho produtivo de poedeiras comerciais leves que receberam ração suplementada com probiótico.

Utilizando probiótico na dieta de poedeiras leves durante estresse térmico, Mohiti Asli et al.
(2007) verificaram que o peso dos ovos, a massa de ovos, o consumo de ração e a conversão alimentar não foram afetados pelos tratamentos. De modo semelhante, Hassanein e Soliman (2010) não observaram efeito de diferentes níveis de levedura (Saccharomyces cerevisiae) na ração sobre o desempenho e a produção de ovos de poedeiras leves de 70 a 79 semanas de idade.

Não houve efeito significativo $(\mathrm{P}>0,05)$ do uso do probiótico sobre a quantidade de ovos perdidos, a porcentagem de gema, albúmen e casca, o peso da casca por unidade de superfície de área (PCSA), a espessura da casca e a porcentagem de matéria mineral na casca dos ovos de poedeiras semipesadas no segundo ciclo de postura (Tab. 3).

Tabela 3. Ovos perdidos, porcentagem de gema, albúmen e casca, peso da casca por unidade de superfície de área, espessura da casca e porcentagem de cinza, segundo a inclusão de probiótico

\begin{tabular}{lcccccc} 
& \multicolumn{5}{c}{ Inclusão de probiótico (\%) } & CV \\
\cline { 2 - 5 } & 0,00 & 0,05 & 0,10 & 0,15 & 0,20 & 39,188 \\
Ovos perdidos (\%) & 1,08 & 0,83 & 0,89 & 0,69 & 1,01 & 3,149 \\
Gema (\%) & 25,12 & 24,94 & 25,74 & 24,58 & 25,40 & 1,212 \\
Albúmen (\%) & 64,91 & 65,09 & 64,58 & 65,36 & 64,72 & $1,2,329$ \\
Casca (\%) & 9,97 & 9,97 & 9,68 & 10,06 & 9,88 & 2,36 \\
PCSA & 8,57 & 8,60 & 8,37 & 8,68 & 8,54 & 2,247 \\
Espessura da casca (mm) & 0,33 & 0,34 & 0,34 & 0,34 & 0,33 & 4,460 \\
Matéria mineral (\%) & 88,38 & 87,48 & 87,12 & 88,64 & 89,13 & 1,685 \\
\hline
\end{tabular}

Resultados semelhantes foram reportados por Giampauli et al. (2005), que não verificaram efeito da utilização de probiótico na ração de poedeiras leves pós-muda, de 70 a 90 semanas de idade, sobre a espessura e a porcentagem de casca. Abdulrahin et al. (1996) não observaram aumento na espessura de casca de ovos de poedeiras leves suplementadas com probióticos à base de Lactobacillus acidophilus. Entretanto,
Hassanein e Soliman (2010) verificaram aumento na espessura da casca de ovos de poedeiras leves ao utilizarem diferentes níveis de levedura (Saccharomyces cerevisiae) na ração, no período de 70 a 79 semanas de idade. Mohiti Asli et al. (2007) também não verificaram efeito da inclusão do probiótico à dieta de poedeiras leves de 62 semanas de idade sobre a qualidade dos ovos, com exceção da porcentagem de gema, 
que foi mais alta em comparação à dietacontrole.

Segundo Lima et al. (2003), a ação dos probióticos parece estar relacionada principalmente a dois fatores, sendo o primeiro a quantidade de microrganismos vivos utilizados e o segundo a presença de estresse nas aves devido às condições de criação. Entretanto, no presente trabalho, a quantidade de probiótico adicionada às rações não influenciou as características produtivas, bem como a qualidade dos ovos das poedeiras semipesadas. Deve-se ressaltar que, no presente experimento, havia aves de diferentes idades alojadas em um mesmo galpão, sendo este um fator estressante ao qual as aves foram submetidas, porém o uso do probiótico não surtiu efeito sobre o desempenho produtivo e algumas características de qualidade dos ovos.

Os resultados de peso dos ovos, índice de gema, cor da gema e unidade Haugh de poedeira semipesadas não foram influenciados $(\mathrm{P}>0,05)$ pela adição crescente de probiótico na ração durante o segundo ciclo de postura (Tab. 4).

Tabela 4. Peso dos ovos, gravidade especifica, índice de albúmen, índice de gema, cor da gema e unidade Haugh (UH), segundo a inclusão de probiótico

\begin{tabular}{lcccccc}
\hline \multirow{2}{*}{ Parâmetros } & \multicolumn{7}{c}{ Inclusão de probiótico (\%) } & CV \\
\cline { 2 - 6 } & 0,00 & 0,05 & 0,10 & 0,15 & 0,20 & CV \\
\hline Peso dos ovos (g) & 65,20 & 65,24 & 65,60 & 66,64 & 65,90 & 1,946 \\
Gravidade específica* & $81,98 \mathrm{a}$ & $82,81 \mathrm{a}$ & $80,10 \mathrm{~b}$ & $82,92 \mathrm{a}$ & $81,35 \mathrm{a}$ & 1,703 \\
Índice de albúmen* & $0,089 \mathrm{a}$ & $0,090 \mathrm{a}$ & $0,088 \mathrm{a}$ & $0,097 \mathrm{~b}$ & $0,086 \mathrm{a}$ & 6,237 \\
Índice de gema & 0,43 & 0,43 & 0,43 & 0,43 & 0,43 & 2,297 \\
Cor da gema & 6,81 & 7,04 & 6,92 & 7,13 & 6,98 & 5,196 \\
UH & 82,38 & 82,59 & 82,65 & 85,74 & 82,05 & 2,760 \\
\hline
\end{tabular}

*Médias seguidas por letras distintas na linha diferem entre si $(\mathrm{P}>0,05)$ pelo teste de Dunnett.

Para a variável gravidade específica, observou-se que a inclusão de $0,10 \%$ de probiótico à base de Lactobacillus acidophilus, Streptococcus faecium e Bifidobacterium bifidum foi menor $(\mathrm{P}<0,05)$ com $0 \%$ de inclusão, afetando negativamente a qualidade do ovo. Os demais níveis de inclusão não diferiram $(\mathrm{P}>0,05)$ da ração testemunha, sem inclusão de probiótico.

$\mathrm{O}$ índice de albúmen foi maior $(\mathrm{P}<0,05)$ para a inclusão de $0,15 \%$ de probiótico à base de Lactobacillus acidophilus, Streptococcus faecium e Bifidobacterium bifidum do que para os demais níveis de inclusão, proporcionando um efeito positivo na qualidade do ovo.

Resultados semelhantes sobre o peso de ovos de poedeiras alimentadas com dietas suplementadas com probiótico foram verificados por Abdulrahim et al. (1996) e Haddadin et al. (1996), que não obtiveram diferença sobre essa característica. De modo semelhante, Pedroso et al. (2001), ao utilizarem Bacillus subtilis como agente probiótico na recria, postura ou durante as duas fases, não observaram melhora no desempenho e na qualidade de ovos de poedeiras de 50 a 66 semanas de idade.

Giampauli et al. (2005) não verificaram efeito da adição de probiótico sobre peso especifico do ovo e unidade Haugh. Ao adicionarem os probióticos Lactobacillus acidophilus e Lactobacillus casei na ração de poedeiras leves, Tortuero e Fernandez (1995) também não observaram benefícios sobre o peso específico dos ovos, entretanto, assim como no presente trabalho, os autores verificaram melhoria na qualidade do albúmen. Nahashon et al. (1994) verificaram melhora na qualidade interna e no peso específico dos ovos, pela presença do probiótico na ração. Há autores que atribuem a ineficiência do uso de probióticos às boas condições sanitárias que o lote gozava por ocasião da realização do trabalho.

Loddi (2000), Pedroso et al. (2001) e Pedroso (2003) ressaltaram que, possivelmente, a falta de desafios proporcionada por um adequado vazio sanitário e por excelentes condições de manejo pode ter impossibilitado a obtenção de resultados 
favoráveis à utilização dos agentes. Entretanto, esse argumento não se adequou ao presente trabalho, o qual foi realizado em uma granja comercial que não realiza a prática de vazio sanitário e, além disso, possui aves de diferentes idades no mesmo galpão e em galpões próximos ao local do experimento.

\section{CONCLUSÕES}

A utilização de probióticos composto por Lactobacillus acidophilus, Streptococcus faecium e Bifidobacterium bifidum não afetou o desempenho e a qualidade dos ovos de galinhas poedeiras semipesadas no segundo ciclo de postura.

\section{REFERÊNCIAS}

ABDULRAHIM, S.M.; HADDADIN, M.S.Y.; HASHLAMOUN, E.A.R. et al. The influence of Lactobacllus acidophilus and bacitracin on layer performance of chickens and cholesterol content of plasma and egg yolk. Br. Poult. Sci., v.37, p.341-346, 1996.

COTTA, J.T.B. Galinha: produção de ovos. Viçosa: Aprenda Fácil, 2002. 260p.

GIAMPAULI, J.; PEDROSO, A.A.; MORAES, V.M.B. Desempenho e qualidade de ovos de poedeiras após a muda forçada suplementadas com probiótico em diferentes fases de criação. Cienc. Anim. Bras., v.6, p.179-186, 2005.

HADDADIN, M.S.Y.; ABDULRAHIM, S.M.; HASHLAMOUN, E.A.R. et al. The effects of Lactobacillus acidophilus on the production and chemical of hens eggs. Poult. Sci., v.75, p.491494, 1996.

HASSANEIN, S.M.; SOLIMAN, N.K. Effect of Probiotic (Saccharomyces cerevisiae) Adding to Diets on Intestinal Microflora and Performance of Hy-Line Layers Hens. J. Am. Sci., v.6, p.159$169,2010$.

HAUGH, R.R. The Haugh unit for measuring egg quality. United States Egg Poult. Magazine, v.43, p.552-555, 1937.

HOLZAPFEL, W.H.; SCHILLINGER, V. Introduction to pre and probiotics. Food Res. Intern., v.35, p.109-116, 2002.
HONG, J.W.; KIM, I.H.; KWON, O.S. et al. Influence of probiotics supplementation on egg quality and excretal anoxious gas in laying hens. J. Anim. Sci. Technol., v.44, p.213-220, 2002.

LIMA, F.V.Z.; PIZAURO JÚNIOR, J.M.; MACARI, M. et al. Efeito do Uso de Probiótico sobre o Desempenho e Atividade de Enzimas Digestivas de Frangos de Corte. Rev. Bras. Zootec., v.32, p.200-207, 2003.

LODDI, M.M.; GONZÁLES, E.; TAKITA, T.S. et al. Uso de probiótico e antibiótico sobre o desempenho, o rendimento e a qualidade de carcaça de frangos de corte. Rev. Bras. Zootec., v.29, p.1124-1131, 2000.

MOHITI ASLI, M.; HOSSEINI, S.A.; LOTFOLLAHIAN, H. et al. Effect of probiotics, yeast, vitamin $\mathrm{E}$ and vitamin $\mathrm{C}$ supplements on performance and immune response of laying hen high environment temperature. J. Poult. Sci., v.6, p.895-900, 2007.

NAHASHON, S.N.; NAKAUE, H.S.; MIROSH, L.W. Production variables and nutrient retention in Single Comb White Leghorn laying pullets fed diets supplemented with direct-fed microbials. $J$. Poult. Sci., v.73, p.1699-1711, 1994.

NEPOMUCENO, E.S.; ANDREATTI, R.L.F. Probióticos e prebióticos na avicultura. In: II Simpósio de Sanidade Avícola, 2000, Santa Maria, RS. Anais... Concórdia, SC, EMBRAPA SUÍNOS E AVES, v.1, p.45-55, 2000.

NUNES, R.V.; POZZA, P.C.; SCHERER, C. et al. Efeito dos teores de cálcio para poedeiras semipesadas durante a fase de pré-postura e no início da postura. Rev. Bras. Zootec., v.35, p.2007-2012, 2006.

PANDA, A.K.; REDDY, M.R.; RAO, S.V.R. et al. Growth, carcass characteristics, immunocompetence and response to escherichia coli of broilers fed diets with various levels of probiotic. Arch. Fur. Geflugelk., v.64, p.152-156, 2000.

PANDA, A.K.; REDDY, M.R.; RAO, S.V.R. et al. Production performance, serum/ yolk cholesterol and immune competence of White Leghorn layers as influenced by dietary supplementation with probiotic. Trop. Anim. Health Prod., v.35, p.85-94, 2003. 
PEDROSO, A.A.; MORAES, V.M.B.; ARIKI, J. Desempenho e qualidade de ovos de poedeiras de 50 a 66 semanas de idade suplementadas com probiótico. Cienc. Rur., v.31, p.683-686, 2001.

PEDROSO, A.A. Comunidade de bactérias do trato intestinal de frangos suplementados com promotores de crescimento. 2003. 108f. Tese (Doutorado em Agronomia) - Pós-Graduação em Ciência Animal e Pastagens, Departamento de Zootecnia, Escola Superior de Agricultura Luiz de Queiroz, Universidade de São Paulo, Piracicaba, SP.
TORTUERO, F.; FERNANDEZ, E. Effects of inclusion of microbial cultures in barley-based diets fed to laying hens. Anim. Feed Sci. Technol., v.53, p.255-265. 1995.

UNIVERSIDADE Federal de Viçosa - UFV. Sistema para Análises Estatísticas e Genéticas. Viçosa, MG: 1999. 59p. (Manual do usuário). 